\title{
Correction to: Epidemiology of Achilles tendon surgery in Italy: a nationwide registry study, from 2001 through 2015
}

Umile Giuseppe Longo ${ }^{1 *}$, Giuseppe Salvatore ${ }^{1}$, Laura Risi Ambrogioni ${ }^{1}$, Eleonora Cella ${ }^{2}$, Vincenzo Candela ${ }^{2}$, Arianna Carnevale ${ }^{3}$, Emiliano Schena ${ }^{3}$, Massimo Ciccozzi ${ }^{2}$, Nicola Maffulli ${ }^{4,5}$ and Vincenzo Denaro ${ }^{1}$

Correction to: BMC Musculoskelet Disord 21, 687 (2020)

https://doi.org/10.1186/s12891-020-03688-2

Following publication of the original article [1], the authors noticed that the author Umile Giuseppe Longo's name was incorrectly modified to "UG Longo" in the final proof. The original article [1] has been updated.

\begin{abstract}
Author details
${ }^{1}$ Department of Orthopaedic and Trauma Surgery, Campus Bio-Medico University, Via Alvaro del Portillo, 200, Trigoria, 00128 Rome, Italy. ${ }^{2}$ Medical Statistics and Molecular Epidemiology, Campus Bio-Medico University, Via Alvaro del Portillo, 200, Trigoria, 00128 Rome, Italy. ${ }^{3}$ Unit of Measurements and Biomedical Instrumentation, Campus Bio-Medico University of Rome, Rome, Italy. ${ }^{4}$ Centre for Sports and Exercise Medicine, Barts and The London School of Medicine and Dentistry, Mile End Hospital, 275 Bancroft Road, London E1 4DG, England. ${ }^{5}$ Department of Musculoskeletal Surgery, University of Salerno School of Medicine, Surgery and Dentistry, 84121 Salerno, Italy.
\end{abstract}

Published online: 10 November 2020

\section{Reference}

1. Longo U, Salvatore G, Risi Ambrogioni L, et al. Epidemiology of Achilles tendon surgery in Italy: a nationwide registry study, from 2001 through 2015. BMC Musculoskelet Disord. 2020;21:687 https://doi.org/10.1186/ s12891-020-03688-2.

The original article can be found online at https://doi.org/10.1186/s12891020-03688-2.

* Correspondence: g.longo@unicampus.it

'Department of Orthopaedic and Trauma Surgery, Campus Bio-Medico

University, Via Alvaro del Portillo, 200, Trigoria, 00128 Rome, Italy

Full list of author information is available at the end of the article

C C The Author(s). 2020 Open Access This article is licensed under a Creative Commons Attribution 4.0 International License, which permits use, sharing, adaptation, distribution and reproduction in any medium or format, as long as you give appropriate credit to the original author(s) and the source, provide a link to the Creative Commons licence, and indicate if changes were made. The images or other third party material in this article are included in the article's Creative Commons licence, unless indicated otherwise in a credit line to the material. If material is not included in the article's Creative Commons licence and your intended use is not permitted by statutory regulation or exceeds the permitted use, you will need to obtain permission directly from the copyright holder. To view a copy of this licence, visit http://creativecommons.org/licenses/by/4.0/. The Creative Commons Public Domain Dedication waiver (http://creativecommons.org/publicdomain/zero/1.0/) applies to the data made available in this article, unless otherwise stated in a credit line to the data. 